\title{
Osseous metaplasia in an ulcerating tubular adenoma of the colon:
}

\section{a case report}

\author{
Victoria White $^{1}$, Aidan G Shaw*2, Gillian M Tierney ${ }^{1}$, Jonathan N Lund ${ }^{2}$ and \\ David Semeraro ${ }^{3}$
}

\author{
Address: ${ }^{1}$ Department of Colorectal Surgery, Derby City General Hospital, Derby, UK, ${ }^{2}$ School of Graduate Medicine and Health, University of \\ Nottingham United Kingdom, Derby, DE22 3DT, UK and ${ }^{3}$ Department of Histopathology, Derby City General Hospital, Derby, UK \\ Email: Victoria White - mzyyvaw@nottingham.ac.uk; Aidan G Shaw* - drshaw@doctors.net.uk; \\ Gillian M Tierney - gillian.tierney@derbyhospitals.nhs.uk; Jonathan N Lund - jon.lund@nottingham.ac.uk; \\ David Semeraro - David.Semeraro@derbyhospitals.nhs.uk \\ * Corresponding author
}

Published: 29 April 2008

Received: 21 December 2007

Journal of Medical Case Reports 2008, 2:130 doi:10.1 I86/1752-1947-2-130

Accepted: 29 April 2008

This article is available from: http://www.jmedicalcasereports.com/content/2/1/130

(c) 2008 White et al; licensee BioMed Central Ltd.

This is an Open Access article distributed under the terms of the Creative Commons Attribution License (http://creativecommons.org/licenses/by/2.0), which permits unrestricted use, distribution, and reproduction in any medium, provided the original work is properly cited.

\begin{abstract}
Introduction: Heterotopic bone is rarely found in the gastrointestinal tract. Here we report a rare case of metaplastic ossification within a benign ulcerating adenoma and review the literature concerning the aetiology.

Case presentation: A 63-year-old woman, who presented with a history of melaena, was found at colonoscopy to have a pedunculated ulcerating polyp. Histological examination demonstrated multiple areas of osseous metaplasia within the polyp stroma.

Conclusion: Heterotopic ossification in colonic adenomas is a particularly rare phenomenon, with the majority of cases occurring within malignant lesions. The suggested mechanisms for its aetiology still remain unclear.
\end{abstract}

\section{Introduction}

Heterotopic bone is rarely found in the gastrointestinal tract. The majority of reported cases are associated with malignant lesions [1-6]. There are few reports of osseous metaplasia in benign colonic polyps [7-12]. Various mechanisms have been proposed on the aetiology yet it still remains poorly understood. Here we report a case of osseous metaplasia in a benign ulcerating adenoma and a review of the literature on suggested mechanisms for its aetiology.

\section{Case presentation}

A 63-year-old woman presented to her general practitioner with a history of intermittent melaena. She was drinking two to three litres of gin per week and was taking ibuprofen for cervical spondylosis. She had a past medical history of alcoholic liver disease and, 6 years previously, a gastroscopy had revealed oesphagitis and duodenitis.

A repeat gastroscopy revealed no abnormality. A colonoscopy was performed which revealed a pedunculated polyp in the proximal transverse colon which was subsequently excised, retrieved and sent for histological examination. The patient has subsequently had no further admissions to hospital or episodes of melaena.

All sections of the specimen demonstrated an adenomatous polyp with a mostly tubular growth pattern and moderate epithelial dysplasia. Areas of surface ulceration with granulation tissue and slough were also noted (Fig- 




\section{Figure I}

Histopathological specimen of the polyp demonstrating adenomatous surface epithelium and slough and inflammatory debris in an area of surface ulceration.

ure 1). The polyp stroma contained multiple areas of osseous metaplasia; the polyp base demonstrated normal mucosa with complete excision margins (Figure 2).

\section{Discussion}

Osseous metaplasia occurs outside the skeletal system in fibrodysplasia ossificans [13]. The incidental finding of bone in histological specimens, although extremely interesting, seems to have no clinical significance $[8,10]$. Heterotopic ossification in colonic adenomas is a particularly rare phenomenon. There are only three other cases

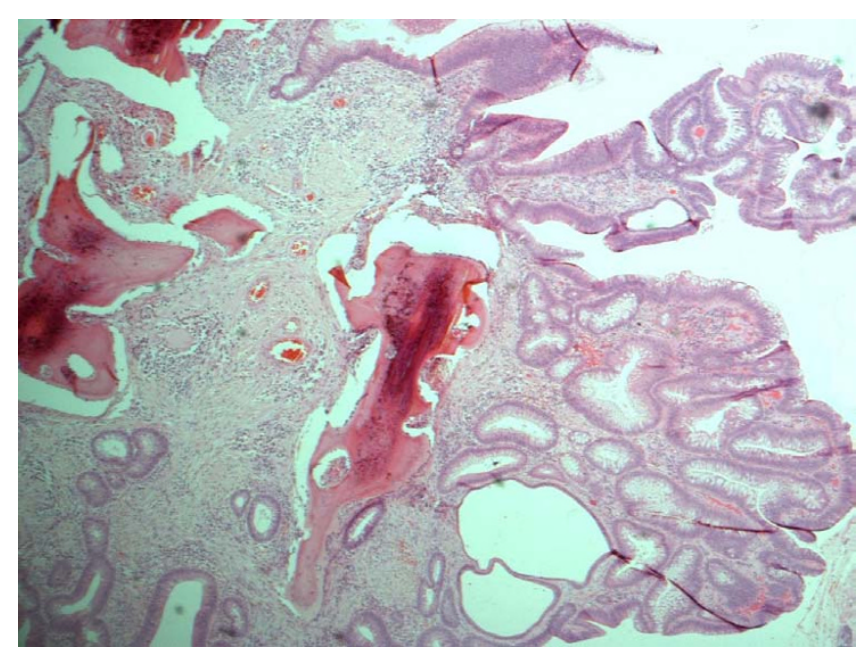

Figure 2

Histopathological specimen of the polyp demonstrating adenomatous surface epithelium and osseous metaplasia with surface osteoclasts. reported of ossification specifically in a tubular adenomas $[7,8,12]$. Osseous metaplasia can also occur in juvenile polyps [8], Peutz-Jeghers Syndrome [11] and inflammatory polyps [9] as well as in malignant lesions [1-6].

How this ectopic ossification occurs is unknown. It may be that the osteoblasts needed to lay down bone differentiate from fibroblasts or other precursor cells. Local osteogenic factors then stimulate these osteoblasts to incorporate collagen fibres already found at the site into new bone. Bone remodelling dependent on the balance between osteoblasts and osteoclasts occurs in areas of ectopic bone as it does in the normal skeleton [9].

The adenomatous polyp removed from our patient had surface ulceration alongside areas of granulation and slough. It may be that the osteogenic stimulation was a result of the inflammatory process. Inflammation has previously been suggested as a trigger in a case of osseous metaplasia in an ulcer in Barrett's oesophagus [10] and in a rectal polyp found to have inflammatory infiltrate alongside the foci of osseous metaplasia [9]. Apostolidis et al. report two theories as to the cause of heterotopic bone found in abdominal incision scars [14]. The first, a suggestion that particles of bone are inoculated into the wound during surgery from the xiphoid process or symphysis pubis, is hard to relate to our case. The second theory, suggesting that osseous metaplasia is the result of differentiation of immature connective tissue to osteoblasts is perhaps more applicable. This differentiation, as Apostolidis et al. suggest, may be a reaction to local injury [14]. The areas of ulceration and granulation tissue found in the polyp from our patient may be as a result of local damage. Osseous metaplasia may have then occurred secondary to this damage. In a case of osseous metaplasia in a benign ovarian cyst the authors also suggest that the bone formation can be due to a reaction to tissue damage and repair [15]. It has also been reported that substances released by abnormal epithelial cells can go on to induce ossification [8]. However, these substances remain to be identified.

\section{Conclusion}

Heterotopic ossification in colonic adenomas is a particularly rare phenomenon, with the majority of cases occurring within malignant lesions. The suggested mechanisms for its aetiology still remain unclear.

\section{Competing interests}

The authors declare that they have no competing interests.

\section{Authors' contributions}

VW and AS wrote the manuscript. GT performed the colonscopy. AS, JL, GT and DS reviewed the literature. All 
authors contributed intellectual content and have read and approved the final manuscript.

\section{Consent}

Written informed consent was obtained from the patient for publication of this case report and accompanying images. A copy of the written consent is available for review by the Editor-in-Chief of this journal.

\section{References}

I. Van Patter HT, Whittick JW: Heterotopic ossification in intestinal neoplasms. Am J Pathol 1955, 71:73-91.

2. Delaney WE, Graham TF: Carcinoma of the colon with ossification. Gastroenterology 1961, 41:277-280.

3. Hall CW: Calcification and osseous metaplasia in carcinoma of the colon. J Can Assoc Radiol 1962, I 3:135-139.

4. Schevach MR: Calcification and ossification in a mucinous adenocarcinoma of the colon: report of the case. Am J Dig Dis 1962, 7:356-359.

5. Lauwers GY, Wahl SJ, Richard GK: Osseous metaplasia in colonic adenocarcinoma. Am J Gastroenterol 1990, 86:382.

6. Papadopoulos MC, Weston J, Ball AB: Osseous metaplasia in caecal adenocarcinoma. J $R$ Soc Med 1998, 91:434-435.

7. Al-Daraji WI, Abdellaoui A, Salman WD: Osseous metaplasia in a tubular adenoma of the colon. J Clin Pathol 2005, 58:220-22I.

8. Groisman GM, Benkov KJ, Adsay V, Dische MR: Osseous metaplasia in benign colorectal polyps. Arch Path Lab Med 1994, I I 8:64-65.

9. Sperling $\mathrm{MH}$, Friedman $\mathrm{CJ}$ : Osseous metaplasia in a benign colon polyp. Gastrointest Endosc 1981, 27:198-199.

10. Haque S, Eisen RN, West B: Heterotopic bone formation in the gastrointestinal tract. Arch Path Lab Med 1996, I 20:666-670.

II. Narita T, Ohmima H, Yokoyama S: Peutz-Jeghers syndrome with osseous metaplasia of the intestinal polyps. Pathol Int 1995, 45:388-392.

12. Cavazza A, Sassatelli R, De Marco L: Osseous metaplasia in an intestinal adenomatous polyp. Case report and review of the literature. Pathologica 1996, 88:5।I-5।3.

13. Shafritz AB, Shore EM, Gannon FH, Zasloff MA, Taub R, Muenke M, Kaplan FS: Overexpression of an osteogenic morphogen on Fibrodysplasia ossificans progressiva. N Engl J Med I996, 335:591-593.

14. Apostolidis NS, Legakis NC, Gregoriadis GC, Androulakakis PA, Romanos AN: Heterotopic bone formation in abdominal operation scars. Am J Surg I98I, I42:555-559.

15. Godbole P, Outram A, Sebire N: Osseous metaplasia in a benign ovarian cyst in association with cloacal anomaly. I Clin Pathol 2005, 58:334-335. http://www.jmedicalcasereports.com/content/2/1/130 